$5 n--10158-1: 3$

iJP85 001519

\title{
Detectability Limits and Precision for Shufflers
}

T. W. Crane

\section{DISCLAIMER}

\begin{abstract}
This report was prepared as an account of work sponsored by an agency of the United States Government. Neither the United States Government nor any agency thereof, nor any of their employees, makes any warranty, express or implied, or assumes any legal liability or responsibility for the accuracy, completeness, or usefulness of any information, apparatus, product, or process disclosed, or represents that its use would not infringe privately owned rights. Reference herein to any specific commercial product, process, or service by trade name, trademark, manufacturer, or otherwise does not necessarily constitute or imply its endorsement, recommendation, or favoring by the United States Government or any agency thereof. The views and opinions of authors expressed herein do not necessarily state or reflect those of the United States Government or any agency thereof.
\end{abstract}

\footnotetext{
NETIGE

PORTIONS OF THIS REPORT ARE ILE ERTE If has been reprodeced from the ines $^{2}$ avallable copy to permit the bicictiest possible availabllity.
} 


\section{CONTENTS}

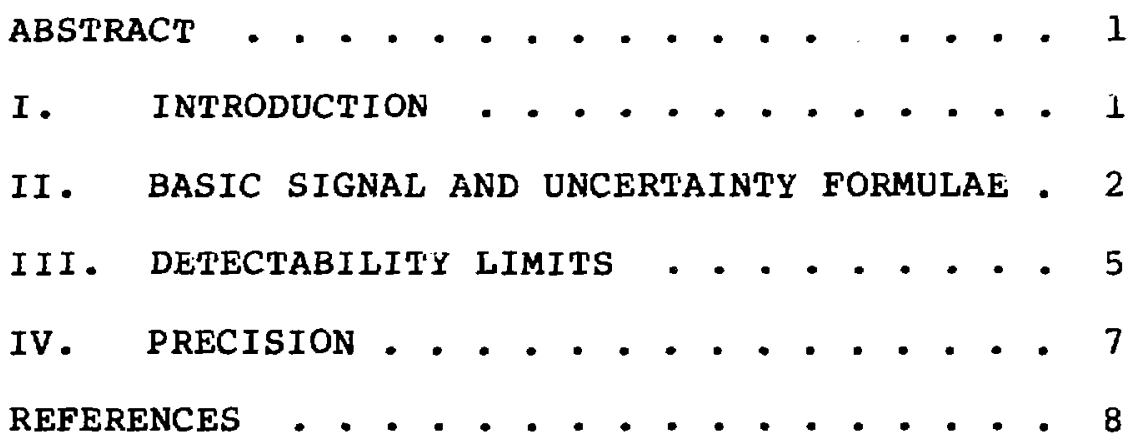


DETECTABILITY LIMITS AND PRECISION FOR SHUFFLERS

by

T. w. Crane

\begin{abstract}
The mathematical formulae for the detectability limit and precision of nonaestructive assay (NDA) instruments have been developea. Definitions are given and references to previous discussions on the subject are cited. The examples are limited to ${ }^{252} \mathrm{Cf}$ shufflers; however, the formalism applies to all NDA instruments. The detectability limit for the Liquid-Sample shuffler test bed is quoted at $4.2 \mathrm{mg} / \mathrm{l}$ of ${ }^{235} \mathrm{U}$ when all the statistical precision effects are incluãed for an $8-\mu g{ }^{252} \mathrm{Cf}$ source and a measurement time of $5 \mathrm{~min}$ is used.
\end{abstract}

\title{
I. INTEODUCTION
}

The detection limit is that quantity of material tnat produces a signal signiticantly above background in a reasonable measurement time.1,2 For nuclear waste management, "significantly" has been defined as three standard deviations, y98 confidence level. The "reasonable" counting time was arbitrarily chosen as $1000 \mathrm{~s}$ for permanently installed in-plant instruments, whereas short times like $10 \mathrm{~s}$ were considered appropriate for hand-held units. 3,4 
Shufflers ${ }^{5}$ (devices for delayed-neutron counting from induced fissions) and, in general, other nondestructive assay (NDA) instruments capable of aetecting a small quantity of material can also exhibit a high statistical precision. Precision is often quoted as one measurement standard deviation divided by the measurement value. 6 This precision value should not be confused with accuracy, 7 which can be and often is sacrificed to achieve a low detectability limit.

In considering the error limits, no attempt is made to include possible systematic or correlated errors that appear as biases. These errors will depend on the NDA instrument as well as on the type and amount of special nuclear material (SNM). References with more detailed discussions of the theory of error estimation are listed at the conclusion of this report. 8-12

\section{BASIC SIGNAL AND UNCERTAINTY FORMULAE}

When NDA instruments measure the signal from an item, some background counts are usually included along with the desired signal. To estimate the background counts accepted with the signal, the background is measured. The estimated background counts can then be subtracted from the signal-plus-backgrcund measurement. The estimated counis can be obtained concurrently with the signal-plus-background measurement (passive gamma-ray counting). 13 Assumed to be constant, one background measurement is adequate for a number of assays. 14 In the case of coincidence counting, the background is negligible and can be ignored. 15 with shufflers, the latter two cases sometimes apply, but one usually needs to measure the background with each assay.

The calculated signal counts are given by the expression

$$
C=\left(S+B_{1}\right)-B_{2} t_{1} / t_{2}
$$




$$
\begin{aligned}
& \text { where } B_{1} \quad=\text { background counted with the signal, } \\
& \mathrm{E}_{2}=\text { backgrouna counted during a separate } r \text { un, } \\
& \mathrm{S}=\text { actual signal, } \\
& \left(S+B_{1}\right)=\text { the recorded signal counts uncorrected for } \\
& t_{1}=\text { signal counting time, and } \\
& t_{2} \quad=\text { background counting time. }
\end{aligned}
$$

The statistical precision in the calculated signal (C) is

$$
\Delta C=\sqrt{\left(s+B_{1}\right)+B_{2} t_{1}^{2} / t_{2}^{2}}
$$

The background $\left(B_{1}\right.$ or $\left.B_{2}\right)$ may comprise contributions $t r o m$ the sample ana exterior sources as well. For shufflers, it is best to measure the background with the sample in place to include effects from sample-related backgrounds. Such neutron backgrounàs include spontaneous fissions from plutonium, uranium, or other elements and $(\alpha, n)$ reactions. This background measurement should precede any irraaiations to avoid having to wait for the longer lived delayed-neutron precursors to decay. Because the longest lived precursor has a half-life of $55.6 \mathrm{~s}$ (Ref. 16), a tew minutes is required for the sample to again reach its original backgrouna level.

The background countea during the passive part of the assay will correctly estimate the background present during the active part. This ability to estimate the background is not an assumption but a fact demonstrated by many examples. 4 It would be possible to incorrectly estimate the background by assaying a aevice such as a neutron generator that was turned on and off during an assay, but this special case is not found in actual situations.

The background counting time $t_{2}$ neea not equal the active counting time $t_{1}$. In most shuffler assay situations, it is aavantageous to have the two times equal. However, as the detectability limit is approached and the background exceeds the signal, 
counting background longer than the signal improves the precision for a given count time. The gains made with this approach are small, and no significant gains are made once the background counting time is about twice that of the signal. 17

The actual signal is estimated by

$$
s=A m t_{1}
$$

where $A=$ calibration constant, and m = quantity of SNM (mass).

If we choose $d$ as the number of standard deviations the signal is to be above background in the allotted time, then

$$
\mathrm{a}=\mathrm{c} / \Delta \mathrm{C}
$$

Substituting the expressions for $C, \Delta C$, and $S$ yields

$$
\begin{gathered}
d=\left[\left(A m t_{1}+B_{1}\right)-B_{2} t_{1} / t_{2}\right] / \\
\sqrt{\left(A m t_{1}+B_{1}\right)+B_{2} t_{1}^{2} / t_{2}^{2}}
\end{gathered}
$$

The background counts can be aivided into two contributions from the SNM and from other sources as follows:

$$
B_{1}=\left(b_{1}+r_{1} m\right) t_{1},
$$


and

$$
B_{2}=\left(b_{2}+r_{2} m\right) t_{2}
$$

where the subscript I refers to the active, induced $f$ issions part of the assay, the subscript 2 refers to the passive part of the assay, $b=$ naturally occurring backgrouna from all sources other than the SNM in the sample, and $r$ = backgrouna rate attributed to the SNM in the sample.

The expression for detectability a [Eq. (5)] is further complicated by Eqs. (6) and (7). Aading masses of SNM in various isotopic ratios is a possible complication but is not usually $\in$ countered at a given facility.

Feconfiguring the expression for detectability a [Eq. (5)], using Eqs. (6) and (7) with $b_{1}=b_{2}=b$ and $r_{1}=r_{2}=r$, now yields

$$
\ddot{a}=A m t_{1} / \sqrt{A m t_{1}+(b+r m)\left(1+t_{1} / t_{2}\right) t_{1}} \text {. }
$$

\section{DETECTABILITY LIMITS}

At the detectability limit of active inscruments, the background from the SNM is generally small, b $>r m$; otherwise, a passive instrument would be more appropriate. Omitting the $r m_{1}$ term from Eq. (8) yielàs

$$
d=A m t_{1} / \sqrt{A m t_{1}+b t_{1}\left(1+t_{1} / t_{2}\right)} .
$$

Equation (9) serves as a starting point for two limiting assumptions about the relative size of the background from sources 
other than SNM. First, if the background is negligibly small, that is, zero, then at the detectability limit

$$
m=\dot{\alpha}^{2} /\left(A t_{1}\right) .
$$

The other limit is a background rate that is much larger than the signal at the detectability limit, b $\gg \mathrm{Am}$. The formula for the detectability limit reauces to

$$
m=\bar{a} \sqrt{b\left(1+t_{1} / t_{2}\right) / A} t_{1}^{1 / 2} .
$$

The last step is to compute the detectability limit including the uncertainty attributed to the signal counts. This last step is done by solving Eq. (9) for. the detectability limit mass $m$ by the quadratic equation formula

$$
m=\left\{d^{2}+d \sqrt{a^{2}+4 b t_{1}\left(1+t_{1} / t_{1}\right)}\right\} / 2 A t_{1} \text {. }
$$

The detectability limit estimations of Eqs. (10)-(12) are compared for the prototype $55-g a l .18$ and Liquid-Sample Shuffler test beds. These two instruments differ greatly in the relative size of the background rate compared with the signal rate. The values of the parameters for the Liquid-Sample Shuffler test bed were observed during test measurements made on July 20, 1983, with a $8-\mu g{ }^{252} \mathrm{Cf}$ neutron source: ${ }^{19}$

$$
\begin{aligned}
& A=44.6 \text { counts } / \mathrm{s} / \mathrm{g} / \mathrm{l}{ }^{235} \mathrm{U}, \\
& \mathrm{b}=0.1 \text { counts } / \mathrm{s}, \\
& \mathrm{d}=3, \\
& \mathrm{t}_{1}=100 \mathrm{~s}, \text { and } \\
& t_{2}=100 \mathrm{~s} .
\end{aligned}
$$


With the listed parameters, the detectability limits for the three cases are

Eq. (10) (no background, $b=0$ )

Eq. (11) (large backgrounā, bo $>$

$$
\begin{aligned}
& \mathrm{m}=0.0020 \mathrm{~g} \\
& \mathrm{~m}=0.0030 \mathrm{~g}{ }^{235} \mathrm{u} / \ell, \\
& \mathrm{m}=0.0042 \mathrm{~g} / \ell,
\end{aligned}
$$$$
\text { Eq. (12) (general case) }
$$

In this case the three estimates are reasonably close. In systems like the 55-gal. barrel prototype shuffler, tnis is not true. Reference 16 quotes the following parameters tor this large shuffler system:

$$
\begin{aligned}
& A=1.7 \text { counts } / \mathrm{s} / \mathrm{g} 235 \mathrm{U}, \text { and } \\
& b=28 \text { counts } / \mathrm{s} .
\end{aligned}
$$

If the counting times are held at $100 \mathrm{~s}$ each and we keep $\dot{a}$ at 3 , then for each of the detectability limit equations we get

$$
\begin{array}{lll}
\text { Eq. (10) (no background, } b=0 \text { ) } & m=0.0529 \mathrm{~g}^{235_{\mathrm{U}}} \\
\text { Eq. (11) (large background, } \mathrm{b}>\mathrm{Am} \text { ) } \mathrm{m}=1.3206 \mathrm{~g}{ }^{235} \mathrm{U} \text {, and } \\
\text { Eq. (12) (general case) } & \mathrm{m}=1.3473 \mathrm{~g}{ }^{235} \mathrm{U} \text {. }
\end{array}
$$

In this case, setting the backgrouna rate to zero as is assumea in Eq. (10) clearly places a detectability limit too low on the instrument. The background rate of 28 counts/s is simply too high, compared with the signal, to ignore. The estimates using Eqs. (11) and (12) are close together because the assumptions maae in deriving Eq. (11) were tollowed.

\section{IV . PRECISION}

Sensitivity is a way of quoting the measurement precision. Sensitivity is defined as the assay standard deviation divided by the assay value. This definition is the inverse of Eq. (4). Dividing the mass uncertainty by the mass (SNM) value is almost the 
same thing, but questions of accuracy cloud the picture. 7 The mass uncertainty may also have contributions from the calibration formula and from the bias corrections based on comparisons with known mass values.

As an example, the sensitivities of the two instruments aiscussed above are compared for a $10-\mathrm{g} 235 \mathrm{U}$ sample. For the Liquid-sample shuffler test bed, this quantity of uranium corresponds to a solution with a concentration of $7.6923 \mathrm{~g} / \mathrm{l}$ of ${ }^{235} \mathrm{U}$ for the $1.3-l$ solution volume. The resulting sensitivities $P$ are

$$
\begin{aligned}
& P=0.54 \%, \text { Liquid-Sample Shuffler test bea, anc் } \\
& P=5.03 \%, 55-g a l \text {. barrel prototype Shuffler test bea. }
\end{aligned}
$$

The disparity in these two instruments is even greater when one considers that the californium neutron source in the Liquid-sample Shuffler test bed was about a tenth the size of the one in the 55-gal.-barrel prototype at the respective measurement times. The Liquid-sample shuffler test bed has the following advantages: (1) the californium neutron source is centered in the liquid tank so that each source neutron is more likely to induce a fission, (2) the smaller size of this test bed leads to a lower background rate, and (3) the hydrogenous liquid helps increase the thermal neutron flux and thereby maximizes the fission probability.

\section{REFERENCES}

1. L. A. Currie, "Limits for Quantitative Detection and Quantitative Determination," Anal. Chem. 40, 586-593 (1968).

2. C. E. Crouthame1, Applied Gamma-Ray Spectrometry, F. Adams and R. Dams, Ed́s., (Pergamon Press, Braunschweig, Hungary, 1970).

3. C. J. Umbarger and L. R. Cowder, "Measurement of Transuranic Solia Wastes at the 10-nCi/g Activity Level," Los flamos scientific Laboratory report LA-5904-MS (March 1975). 
4. T. W. Crane, "Measurement of Uranium anć Plutonium in Solid Waste by Passive Photon or Neutron counting and Isotopic Neutron Source Interrogation," Los Alamos Scientific Laboratory report LA-8294-MS (March 1980).

5. H. O. Menlove, "Modulated 252Cf Assay System, 'Shuffler"," in "Nuclear Analysis Research and Development Program Status Report, January-April 1974," G. Robert Keepin, Ed., Los Alamos Scientific Laboratory report LA-5675-PR (August 1974).

6. T.W. Crane, "lest and Evaluation Results of the $252 \mathrm{Cf}$ Shuffler at the Savannah River Plant," Los Alamos National Laboratory refort LA-8755-MS (March 1981).

7. "American National Standarás Guide for Precision anä Accuracy Staterients" (American National Standarás Institute, Inc., New Yorkj, rough draft June $8,1983$.

8. W. E. Deming, Statistical Aajjustment of Data (John wiley \& Sons, Inc., New York, 1943).

9. J. Orear, "Notes on Statistics for Physicists," University of California, Berkeley Radiation Laboratory report UCRL-8417 (1958).

10. N. R. Draper and H. Smith, Applied Regression Analysis (John wiley \& Sons, Inc., New York, 1967).

11. P. R. Bevington, Data Reduction and Error Analysis for the Physical Sciences (McGraw-Hill Book Company, New York, 1969).

12. "American National Standards Guide to Calibrating Nondestructive Assay Systems," ANSI N15.20-1975 (American National Standarós Institute, Inc., New York, 1975).

13. R. H. Augustson anà T. D. Reilly, "Fundamentals of Passive Nonàestructive Assay of Fissionable Material," Los Alamos Scientific Laboratory report LA-5651-M (September 1974).

14. I. K. Li, "Automated 1n-Plant Neasurement of Plutoniumi Solutions in a Plutonium Purification Process," Nucl. lechnol. 55, 674-682 (1981).

15. H. O. Menlove, O. K. Holbrooks, and A. Famalho, "Inventory Sample Coinciāence Counter Manual," Los Alamos National Laboratory report LA-9544-M (November 1982).

16. R. W. Waldo, R. A. Karam, anō R. A. Meyer, "Delayed Neutron Yields: Time Dependent Measurements and a Preáictive Model," Phys. Rev. C 23, 1113-1127 (March 1981). 
17. S. D. Gardner, Eä., Nuclear Safeguards Research and Deve1opment Program Status Report, April-June 1979," Los Alamos Scientific Laboratory report LA-7991-PR (November 1979), Pp 10-11.

18. T. W. Crane, "Prototype ${ }^{252} \mathrm{Cf}$ Shuffler for Neutron Interrogation of 55-gal Barrels," in "Nuclear Safeguarás Research and Development Program Status Report, January-April 1977," J. L. Sapir, Comp., Los Alamos Scientific Laboratory report LA-6849-PR (August 1977).

19. T. W. Crane and P. R. Coliinsworth, "Fissile Solution Shusfler Patent Application," Los Alamos National Laboratory memoranaum Q-1-83-693/0704D to $N_{\text {. }} V$. Fuller (September 1, 1983). 